\title{
Too Immature to Vote?
}

\author{
A Philosophical and Psychological Argument to Lower the Voting Age
}

Tommy Peto*

\begin{abstract}
This article argues in favour of lowering the voting age to 16. First, it outlines a respect-based account of democracy where the right to vote is grounded in a respect for citizens' autonomous capacities. It then outlines a normative account of autonomy, modelled on Rawls's two moral powers, saying what criteria must be met for an individual to possess a (pro tanto) moral right to vote. Second, it engages with empirical psychology to show that by the age of 16 (if not earlier) individuals have developed all of the cognitive components of autonomy. Therefore, since 16- and 17-yearolds (and quite probably those a little younger) possess the natural features required for autonomy, then, to the extent that respect for autonomy requires granting political rights including the right to vote - and barring some special circumstances that apply only to them - 16- and 17-yearolds should be granted the right to vote.
\end{abstract}

Keywords: voting age, children's rights, youth enfranchisement, democracy, votes at 16

\section{Introduction}

Over the last decade, more and more countries have allowed 16- and 17-year-olds to vote. Nicaragua and Brazil were early adopters, allowing 16-year-olds to vote in all elections from the 1980s. In the mid-2000s, 16year-olds were given the vote in the Isle of Man (2006), Austria (2007), Guernsey (2007), Jersey (2008) and Ecuador (2008). More recently, 16-year-olds have been granted the vote in Argentina (2012) and Malta (2013), and in Scotland (2014), where they can vote in local and Scottish parliamentary elections, and voted in the 2014 independence referendum, although they cannot vote in UK-wide elections. Other countries allow 16-year-olds to vote in some elections but not others: 16-year-olds can vote in state or municipal elections in some German Länder and Swiss cantons; Estonia has allowed 16-yearolds to vote in local elections since 2015; and 16-yearolds could vote in the official Catalan self-determination referendum of 2014. Most countries, however, are still

University of Oxford. Acknowledgements: I would like to thank Matthew Clayton and Zofia Stemplowska for comments on earlier work that developed into this article, Daniel Butt for his comments and for wide-ranging discussions of some of the issues explored here, and two anonymous reviewers who helped improve the article immensely. reticent: Luxembourg rejected a reduction in the voting age in a referendum in 2015, and the UK parliament debated but rejected allowing 16-year-olds to vote in the EU referendum.

So far, research into the voting age has seen the right to vote as grounded in political knowledge and political interest/apathy, with empirical research investigating whether 16- and 17-year-olds have enough political knowledge, or enough political interest, to vote. ${ }^{1}$ However, in this article, I will examine an alternative liberal view: that the right to vote is grounded not in knowledge but in moral autonomy and that all those who possess the capacities for autonomy have a pro tanto right to vote. ${ }^{2}$ This article therefore sets out an account of autonomy, and the criteria individuals need to meet to count as possessing autonomy, and then uses empirical psychology to see whether adolescents meet those criteria. In fact, developmental psychologists are clear that adolescents (from 14/15) are almost indistinguishable from adults in their general cognitive abilities. ${ }^{3}$ There-

1. Tak Wing Chan and Matthew Clayton, "Should the Voting Age Be Lowered to Sixteen? Normative and Empirical Considerations," Political Studies 54, no. 3 (2006), pp. 533-58; Tommy Peto, "Why the Voting Age Should Be Lowered to 16," Politics, Philosophy \& Economics 17, no. 3 (2018), pp. 277-97; Eva Zeglovits and Julian Aichholzer, "Are People More Inclined to Vote at 16 Than at 18? Evidence for the FirstTime Voting Boost among 16- to 25-Year-Olds in Austria," Journal of Elections, Public Opinion and Parties 24, no. 3 (2014), pp. 351-61; Eva Zeglovits and Martina Zandonella, "Political Interest of Adolescents Before and After Lowering the Voting Age: The Case of Austria," Journal of Youth Studies 16, no. 6 (2013), pp. 1-21; Eva Zeglovits, “Voting at 16 ? Youth Suffrage Is Up for Debate," European View 12, no. 2 (2013), pp. 249-54; Johannes Bergh, “Does Voting Rights Affect the Political Maturity of 16- and 17-Year-Olds? Findings from the 2011 Norwegian Voting-Age Trial," Electoral Studies 32, no. 1 (2013), pp. 90-100; Markus Wagner, David Johann, and Sylvia Kritzinger, “Voting at 16: Turnout and the Quality of Vote Choice," Electoral Studies 31, no. 2 (2012), pp. 372-83; Daniel Hart and Robert Atkins, "American Sixteen-and Seventeen-Year-Olds Are Ready to Vote," The ANNALS of the American Academy of Political and Social Science 633 no. 1 (2011).

2. 'pro tanto' because this right is perhaps sometimes legitimately suspended or infringed, e.g. in times of national emergency. I do not address the question of when, if ever, such circumstances arise.

3. Joe Coleman, "Answering Susan: Liberalism, Civic Education, and the Status of Younger Persons," in The Moral and Political Status of Children, ed. David Archard and Colin M. Macleod, 1 online resource (Oxford: Oxford University Press, 2002), pp. viii, 296 pages, 168. Also David Moshman, Adolescent Psychological Development: Rationality, Morality, and Identity (Mahwah, NJ: Lawrence Erlbaum Associates, 1999), p. 40; Michael D. A. Freeman, The Moral Status of Children: Essays on the Rights of the Child (Boston: Martinus Nijhoff, 1997), p. 28; M. Schmidt and N. Reppucco, "Children's Rights and Capacities," in Children, Social Science, and the Law, ed. Bette L. Bottoms, 
fore, since 16- and 17-year-olds (and perhaps even younger adolescents) possess the same cognitive capacities as adults, they meet the criteria for the possession of autonomy. Thus, because autonomy grounds a (pro tanto) right to vote, 16 - and 17 -year-olds have a pro tanto right to vote. ${ }^{4}$

One point worth clarifying is that this investigation into the voting age is not an investigation into what Dahl calls the 'problem of the unit' or the 'boundary problem'. 5 'The problem of the unit is, what persons have a rightful claim to be included in the demos? When we say a group of individuals, or 'the people', have a right to democratic self-rule, who is included in 'the people'? This is distinct from what I shall call the qualification question: which members of that people/association/ unit should be permitted to vote? Whether the problem of the unit is solved by the 'all affected' principle (everyone affected by state actions should be included), the 'all subjected' principle (everyone subject to the laws of the state should be included), an appeal to historic boundaries, or an appeal to national identity and self-determination, there remains the question of who within that unit is qualified to vote. Therefore, determining whether an individual has the right to vote within a particular state/association is a two-step process: (i) are they a member of the relevant group? (ii) are they the kind of individual who in general merits the right to vote? This article speaks only to the second question. My argument is that 16-year-olds should, in general, be allowed to vote. It is a separate question whether for, say, Dutch elections, it is those 16-year-olds who are affected/coerced by the policies of the Dutch government, who are resident within the Netherlands or who are Dutch nationals who should be allowed to vote.

I also want to make two methodological points. First, I take as a general assumption that all adult citizens, or the overwhelming majority of them, possess the natural features required for the right to vote. Therefore, to establish whether adolescents possess the right to vote, we can compare their psychological capacities to adults'. When defining the criteria for autonomy, there is the threshold question: what level of psychological capacity is required to meet those normative criteria? Sorites' paradoxes abound. But if adolescents reach the same level of autonomy as average adults, then, assuming adults deserve the right to vote, so too do adolescents. In fact, the threshold will be below the level of an average adult. After all, adults with capacities significantly below average still possess the vote. Of course, by assuming that adults generally deserve the vote, this article will not convince an anti-democrat that 16 - and 17 -

Margaret Bull Kovera, and Bradley D. McAuliff (Cambridge, UK; New York: Cambridge University Press, 2002), p. 160

4. For simplicity, I will usually refer to 'the right vote' without adding 'pro tanto' each time.

5. Robert A. Dahl, Democracy and Its Critics (New Haven: Yale University Press, 1989), pp. 193, 119 and 146-47. See also Goodin's 'problem of "constituting the demos"', Robert E. Goodin, "Enfranchising All Affected Interests, and Its Alternatives," Philosophy \& Public Affairs 35, no. 1 (2007), pp. 40-68. year-olds should be allowed to vote. But for democrats, the argument cantilevers from the claim that adults should have the vote to the claim that 16 - and 17-yearolds should have the vote.

Second, this article examines empirical psychology rather than neuroscience to assess teenagers' capacities. Neuroscientific results are sometimes quoted in debates about the voting age. For example, Chan and Clayton, and Dawkins and Cornwell quote research showing that adolescents' frontal lobes have not yet settled into an adult structure. ${ }^{6}$ More specifically, there is less development in the connections in the fronto-parietal-striatal brain system (localised primarily in the lateral prefrontal cortex, inferior parietal lobe and anterior cingulate cortex). ${ }^{7}$ Since the frontal lobes are associated with executive functions such as the cognitive and emotional control needed to make cool and rational decisions, they claim this shows that teenagers do not merit the right to vote. ${ }^{8}$ That said, others dispute whether these neurological differences are a significant factor in political decision-making. ${ }^{9}$ However, this article engages with the psychological evidence rather than the neurological evidence. The reason is that since we define autonomy in terms of powers of reason, we should investigate directly whether adolescents possess those powers of reason (and the cognitive control to exercise them). If adolescents lack key reasoning abilities, they lack the relevant autonomy to vote, even if they have 'fully developed' brains. And if they possess these powers of reason, then they do possess the relevant autonomy, even if they have otherwise 'undeveloped brains'. Neurology may provide interesting insights into the bases of cognition, but it is not itself of direct normative relevance. ${ }^{10}$ For that reason, I focus on the psychology.

\subsection{Outline}

Section 2 lays out how autonomy is linked to the right to vote, and the criteria for possessing autonomy. It uses the Rawlsian account of the 'two moral powers' to provide the criteria for possessing the relevant kind of autonomy. Section 3 lays out which parts of empirical psychology are relevant to the two moral powers. Sections 4-8 provide an empirical outline of adolescent psychological capabilities through the normative lens of the two moral powers. In turn, they examine five norma-

6. Chan and Clayton, "Should the Voting Age Be Lowered to Sixteen? Normative and Empirical Considerations," p. 357; Richard Dawkins and R. Elizabeth Cornwell, “Dodgy Frontal Lobes, Y'dig? The Brain Isn't Ready to Vote at 16," The Guardian, 13th December 2003.

7. Laurence Steinberg, "Adolescent Brain Science and Juvenile Justice Policymaking," Psychology, Public Policy, and Law 23, no. 4 (2017), p. 414.

8. For results on neurological development, see J. N. Giedd et al., "Brain Development During Childhood and Adolescence: A Longitudinal Mri Study," Nature Neuroscience 2, no. 10 (Oct 1999), pp. 861-63; V. F. Reyna and F. Farley, "Risk and Rationality in Adolescent Decision Making: Implications for Theory, Practice, and Public Policy," Psychology Science in the Public Interest 7, no. 1 (2006), pp. 1-44

9. Hart and Atkins, "American Sixteen-and Seventeen-Year-Olds Are Ready to Vote," p. 220.

10. See also Steinberg, "Adolescent Brain Science and Juvenile Justice Policymaking," p. 418. 
tively relevant components of cognitive thinking: logical reasoning, empirical reasoning, decision-making, argumentation, and moral reasoning. Each section (i) defines them theoretically and identifies their sub-components; (ii) discusses their normative relevance; and (iii) provides an empirical comparison of adolescents and adults. Together, these sections show that older adolescents (14-16) and adults possess the two moral powers equally. Section 9 then examines 'hierarchical control' and assesses the claim that although adolescents have the same cognitive abilities as adults, they are more impulsive or emotional and so should not be granted the vote. While Section 9 accepts the empirical claim, it denies that this should be a bar to adolescent voting, since voting does not usually occur in the type of emotionally intense setting that some adolescents struggle with. Therefore, to the extent that respect for the two moral powers implies a right to vote for adults, so too should it for adolescents. First, let us examine autonomy and how it links to voting rights.

\section{Autonomy and the Right to Vote}

This section outlines the view that the right to vote is grounded in a respect for individual autonomy and, in so doing, provides an account of the criteria that, on one major liberal tradition, an individual must meet to possess autonomy and therefore to deserve the right to vote. First, I outline the autonomy-respecting view of democracy. Then I outline the Rawlsian account of autonomy, which is grounded in the 'two moral powers', and I link it to the right to vote. The two moral powers then provide us with the qualification criteria for inclusion in political decision-making. This section is, of course, not a fully fleshed out liberal defence of democracy: that would require (much) more space than can be given here. But it does provide an outline of how this account of democracy works and the qualification criteria for the franchise under this account.

A certain classic view of democracy takes democracy to be implied by basic values of respect or fairness. ${ }^{11}$ This account says that all competent individuals possess the right to direct their own lives autonomously. This implies that they deserve a say in those decisions that regulate their lives and/or deserve to have decisions made about them justified to them in some way. Principles of fairness then imply that one individual's voice should have the same weighting as anyone else's. Therefore, denying a competent citizen the right to vote does two wrongs: (i) it violates their equal standing as a citizen; (ii) it fails to respect that citizen as an autonomous decision maker. These two effects can be wrong

11. Francis Schrag, "Children and Democracy: Theory and Policy," Politics, Philosophy \& Economics 3, no. 3 (2004), pp. 365-79, 366; Ronald Dworkin, Justice for Hedgehogs (Cambridge, MA: Belknap Press, 2011), p. 379. either derivatively for recognition-type reasons or intrinsically as a violation of basic principles. Either way, mature/competent citizens deserve consultation and equal standing, and it is wrong to deny them those things. This is true regardless of whether those individuals also happen to share an independent characteristic (like age) with other people who perhaps do not deserve equal standing. Thus, there is a rights violation, a pro tanto wrong, when we deny the vote to competent people, and a fortiori there is a pro tanto wrong when we deny the right to vote to competent 16- to17-year-olds.

So, what are the capacities required to possess autonomy? One prominent liberal account of autonomy, which shares features with many other liberal accounts, is the Rawlsian one. ${ }^{12}$ The Rawlsian account of autonomy is based on the two moral powers:

i. A capacity for a sense of justice: 'the capacity to understand, to apply, and to act from (and not merely in accordance with) the principles of political justice';

ii. A capacity for a conception of the good: 'the capacity to have, to revise, and rationally to pursue a conception of the good'. ${ }^{13}$

Let's first examine the second moral power. All major accounts of autonomy encompass something like this: a self-imposed authentic standard of excellence (J.S. Mill), a conception of what gives value to life (R. Dworkin), projects and goals (Raz). Griffin characterises a 'human existence' as involving reflection and assessment. We 'form pictures of what a good life would be [and] ... we try to realise these pictures'. ${ }^{14}$ He concludes that, "what ... [gives] dignity to human life is our capacity to choose and to pursue our conception of a worthwhile life'. ${ }^{15}$ The basic idea is that, to be autonomous, you must be, amongst other things, self-determining your life. And to do this, you must be determining your life according to some self-imposed standard or set of goals. Put differently, you must be part-author of your life. And to be part-author of your own life, you must have a (partial) script. The 'conception of the good' is that script (even if that script is constantly revised, edited and rewritten). We can use Rawls's conception of this idea, embodied in the 'second moral power', because it usefully splits the power into different component abilities: 'the capacity to have, to revise, and rationally to pursue a conception of the good', which we can then use to match against specific psy-

12. Strictly speaking, in the Rawlsian framework, the two moral powers are the basis of moral personhood/citizenship rather than components of 'autonomy', but it can play a similar role to autonomy in our overall argument. See Catherine Audard, "Autonomy, Moral," in The Cambridge Rawls Lexicon, ed. Jon Mandle and David A. Reidy (Cambridge; New York: Cambridge University Press, 2015a), pp. xxiii, 897 pages and "Autonomy, Political," in The Cambridge Rawls Lexicon, ed. Jon Mandle and David A. Reidy (Cambridge; New York: Cambridge University Press, 2015b), pp. xxiii, 897 pages.

13. John Rawls, Justice as Fairness: A Restatement (Cambridge, MA; London: Harvard University Press, 2001), pp. 18-19.

14. James Griffin, On Human Rights (Oxford: Oxford University Press, 2010), p. 32.

15. Ibid., p. 44 
chology capabilities later. Similarly, Rawls gives a precise definition of 'conception of the good', saying it is:

an ordered family of final ends and aims which specifies a person's conception of what is of value in human life or, alternatively, of what is regarded as a fully worthwhile life. ${ }^{16}$

Therefore, the Rawlsian second moral power embodies the same idea as the other major liberal accounts of autonomy mentioned earlier while providing a precision that is helpful when we turn to empirical psychology. This is why we should use it when investigating adolescent autonomy.

It is worth clarifying a few things about the second moral power. This 'plan of life' or 'conception of the good' does not need to be good in an objective sense. Indeed, some people's lifestyle and life goals may seem objectively objectionable. But the whole point of selfauthorship is that we can decide and construct for ourselves what is good for us. Any dream will do (although we may restrict how you pursue that dream). ${ }^{17}$ This may sound rather grand, but it need not be. R. Dworkin provides the following image:

Each person follows a more or less articulate conception of what gives value to life. The scholar who values a life of contemplation has such a conception; so does the television-watching, beer-drinking citizen who is fond of saying "This is the life", though of course he has thought less about the issue and is less able to describe or defend his conception. ${ }^{18}$

One's life need not have a unity, or a single rigid plan (though it may do). The ideal of autonomy is about being able to fashion one's life through one's own goals and decisions, even as those goals shift and change. ${ }^{19}$ To the extent you have formed goals and plans, or assessed what you want to do in a given situation, you have been (to various degrees of sophistication and explicitness) reasoning about 'the good'. Like Monsieur Jourdian in Molière's The Bourgeois Gentleman, who discovers that 'these forty years now I've been speaking in prose without knowing it!', we are using fancy concepts used to describe something which, at its heart, is familiar.

How does the second moral power link to the right to vote? Respect for autonomy, and for the second moral power specifically, means letting people make decisions about themselves. It would be inconsistent with respect for autonomy to substitute your own judgment for someone else's about their own good: claims that 'I

16. Rawls, Justice as Fairness: A Restatement, pp. 18-19; also Pete Murray, "Conception of the Good," in The Cambridge Rawls Lexicon, ed. Jon Mandle and David A. Reidy (Cambridge: Cambridge University Press, 2015).

17. You may not, for example, sell your brother into slavery to pursue your dream.

18. Ronald Dworkin, "Liberalism," in A Matter of Principle (Oxford: Clarendon Press, 1986), p. 191.

19. Joseph Raz, The Morality of Freedom (Oxford: Clarendon Press, 1986), pp. 370-71. respect you as a chooser but will deny you any choice' would be disingenuous. In particular here, the second moral power involves the ability to make judgments about one's own interests. Respect for autonomy requires a respect for how individuals identify and pursue their own interests. If your mother were devoted to your interests, but nevertheless ignored how you perceive those interests, she would be lacking in respect for you or, more specifically, for your autonomous ability to define and identify your own interests. This would be true even if your judgment turned out to be mistaken and hers correct. To respect someone as a person is to take their own view of themselves seriously. As Benn puts it, you would have:

every reason to resent the indulgent dismissal of [your] point of view, "Yes, dear, but Mummy knows best," even in the case that Mummy does. ${ }^{20}$

This means that when certain decisions are made about an individual or for an individual, that decision-making process should include their own judgment about themselves. For most self-regarding decisions, this implies the liberal position that people may make such decisions uninhibited. But when decisions must be made about people collectively through political institutions, including individuals' own judgments about themselves means giving them a voice in that process, something usually formalised and enshrined in the right to vote. ${ }^{21}$ The people must be allowed to define and express their own interests, and not have their interests determined for them by technocrats or despots.

Next, let's examine the first moral power, which covers the ability to reason about justice, apply principles of justice and, as I would add to it, reason about and apply moral principles more generally. Including the first moral power helps us make sense of the idea of moral autonomy. Self-government encompasses the ability to decide not only how you would like to live your life, but also how you ought to live your life. The capacity to reason about justice and morality captures the idea that to be truly morally self-governing we must be able to impose moral laws on ourselves. This ideal is Kantian in flavour: for a rational (and autonomous) being to qualify as such, it must be able to construct, recognise and follow moral laws.

How does the first moral power link to the right to vote? The first moral power helps make sense of 'political autonomy'. This is the idea that humans are fundamentally politically free. The ideal of political autonomy is what makes liberals concerned about state legitimacy and state coercion. Political autonomy is the idea that

20. Stanley I. Benn, A Theory of Freedom (Cambridge: Cambridge University Press, 1988), p. 105.

21. Perhaps there are ways other than the vote that protects people's moral right to self-government and includes them in political decision-making. It may not be an analytic truth that the moral right to inclusion in political decision-making entails the right to vote, but the right to vote does seem to be the best method we have come up with for instantiating that moral right. Dworkin, Justice for Hedgehogs, pp. 379-400. 
we, as individuals, are politically self-governing. Individuals can deliberate on, construct and self-impose rules of political morality. Respecting that ability to politically self-govern means recognising individuals' political freedom. This gives rise to a problem: if individuals are fundamentally politically self-governing, then why may a coercive institution, such as the state, govern them politically? One way to (at least partially) address this problem is to include those individuals in the political decision-making mechanisms of the state. ${ }^{22}$ This is a different argument from the one earlier about letting people define their own interests and including them in decisions that affect their interests. Political rights, such as the right to vote, presuppose an ability to reason not merely about what we want individually, but about the right and the good more generally. Mirroring the above argument about the second moral power, technocrats and rulers may not impose their own version of the right and the good on people who possess the capacity to make their own judgments about the right and the good. Therefore, in political decisions, which involve imposing views of justice and morality on a society, respect for autonomy means including all members of that society who can make decisions about justice and morality. To exclude those with that capacity is to disrespect that capacity.

Therefore, autonomy, as exemplified here by the two moral powers, grounds the right to vote in two ways: first, individuals who can define and pursue their own interests must be included in decisions about their choices and their interests; and, second, individuals who can reason about justice must be included in decisions about the rules of justice that apply to them. Individuals who possess the two moral powers therefore possess these moral rights to inclusion in political decision-making. So, to assess whether 16- and 17-year-olds should possess the right to vote, we should assess empirically whether they possess the two moral powers.

\subsection{Autonomy and Political Maturity}

How does the autonomy approach here relate to the political maturity approach (emphasising knowledge and interest in politics) more common in the political science literature? The autonomy approach fits broadly within a Kantian or Republican tradition, in which political rights come from citizens' dignity, personhood or autonomy. Non-democratic forms of government are objectionable because they stand the state in the wrong kind of relationship to its citizens.

The political maturity approach appears to have roots in epistocracy, that is, a tradition which holds that political power should be wielded by those best able to make political decisions. The concern in this tradition is often good outcomes. Of course, many in the epistocratic tradition are not democrats: Plato, for example, argued that political power should be restricted to an elite class of the wise and just. However, there are democratic arguments grounded in the wisdom of the crowd, rather

22. Ibid., p. 385 than the wisdom of the elite. Aristotle, retaining Plato's concern for just and wise government, argued that larger groups are more likely to make correct decisions than smaller groups, even if additional members are less wise than the existing members, so long as the new voters are wise enough. ${ }^{23}$ Condorcet's jury theorem similarly demonstrates that adding more members to a group increases the chances that a collective decision is correct, so long as each additional voter is more than $50 \%$ likely to make the correct decision. This theorem, as with the Aristotelian argument, is sometimes used to justify democracy, but it would only suggest extending the franchise when the additional voters are sufficiently competent. The most significant democratic theorist in the epistocratic tradition is J.S. Mill. Concerned about granting votes to an uneducated mob, he argued that the educated should be given extra votes and advocated knowledge requirements for the franchise (albeit with a low bar):

I regard it as wholly inadmissible that any person should participate in the suffrage without being able to read, write, and, I will add, perform the common

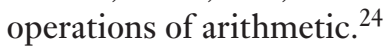

The concern about whether people can make sufficiently competent political decisions seems to animate those who use knowledge and interest in politics to either exclude or include adolescents from voting. Chan and Clayton, for example, argue that, 'we have good reasons of justice to prevent the incompetent from voting', ${ }^{25}$ and that if the voting age were lowered:

too many of them [16- and 17-year-olds] would vote and do so incompetently, in a way that would be detrimental to our democracy. ${ }^{26}$

The political maturity approach can therefore, broadly, be seen as part of the same epistocratic tradition as J.S. Mill: concerned about good governance and restricting the vote from those who may damage the overall decision-making quality of the polis.

How do the autonomy and political maturity approaches differ? First, the political maturity approach takes interest in politics to be of fundamental importance, whereas the autonomy approach takes it to be morally irrelevant (although an interest in politics could be one of many ways that individuals exercise and develop their moral reasoning abilities). While Chan and Clayton, among others, claim political apathy disqualifies teenagers from the franchise, the autonomy approach asks instead whether they have the relevant psychological

23. David M. Estlund, "Why Not Epistocracy?", in Desire, Identity, and Existence: Essays in Honor of T.M. Penner, ed. Naomi Reshotko and Terry Penner (Kelowna, BC: Academic Print. \& Pub., 2003), pp. 55-57.

24. John Stuart Mill, "Considerations on Representative Government," in Essays on Politics and Society, ed. John M. Robson, Collected Works of John Stuart Mill (London: Routledge \& Kegan Paul, 1977), p. 470.

25. Chan and Clayton, "Should the Voting Age Be Lowered to Sixteen? Normative and Empirical Considerations," p. 539.

26. Ibid., p. 537 
capacities. Rights are not generally denied to those uninterested in using them. To deny someone the vote just because they are not interested in politics is to disrespect their autonomy, because you are unilaterally substituting their judgment with yours about what is good for them and right for the community. Of course, people who are uninterested in politics may let others make those judgments for them by not voting. But choosing to do so is an instantiation of their autonomy rather than an infringement of it. The autonomy approach would grant the apathetic this choice because to do so is to respect them as choosers.

The second difference between the political maturity and autonomy approaches is in their attitude towards knowledge. Those in the epistocratic tradition see knowledge, or education, as key qualifications for the franchise because it helps voters to collectively make better decisions. The autonomy approach is concerned about the state standing in the right kind of relation to those whom it governs, and holds that, generally speaking, it may not rule over autonomous citizens who have no say in it, even those citizens who are uneducated. ${ }^{27}$

However, both accounts do care about competence/ development to some extent. In neither account do rocks, plants or animals qualify for the franchise. So there must be some natural features possessed by (adult) humans that qualify them for the vote. Therefore, both care about children reaching some threshold to qualify for the vote. But the approaches have different attitudes to the threshold. On the autonomy account, reaching the threshold means reaching a political status that is morally incompatible with non-democratic rule. On the epistocratic account, reaching the threshold means reaching a level of competence/ability such that the individual can usefully contribute to democratic and political decision-making.

Therefore, the political maturity approach broadly lies within an epistocratic tradition that cares about democratic decisions having good outcomes or good deliberative processes, and sees knowledge and interest as of fundamental importance. The autonomy approach, however, sees interest as lacking fundamental importance in the franchise and is generally hostile to knowledge requirements that may lead to the domination or disrespect of citizens.

Since we are adopting the autonomy approach here, let's now examine which psychological capacities correspond to the two moral powers which constitute autonomy and therefore which capacities we must measure to investigate whether 16- and 17-year-olds should possess the vote.

27. For one such opposition to knowledge requirements, see David $M$ Estlund, Democratic Authority: A Philosophical Framework (Princeton, NJ: Princeton University Press, 2008), pp. 206-22.

\section{Connecting Psychology to the Two Moral Powers}

In this section, I outline what psychological capacities are presupposed by the two moral powers. These boil down to five: logical/syllogistic reasoning, empirical reasoning, decision-making, argumentation and moral reasoning. In the following sections, we will see that each component is possessed equally by adolescents and adults, and therefore that adolescents (or, at least, older adolescents) fully possess the two moral powers. Let's take each moral power in turn.

The second moral power is the capacity to have, to revise and rationally to pursue a conception of the good, which specifies an ordered family of final ends and aims. The full ability to have a conception of the good requires moral reasoning abilities, since you must internalise and understand moral norms. Once you have internalised normative beliefs, you can be said to 'have' a theory of the good.

The capacity to revise a conception of the good requires a combination of logical/syllogistic reasoning, moral reasoning and argumentative ability. To revise a conception of the good, you must understand the rules of logic to make rational and reasonable inferences; you must be able to reason in moral terms to assess the contents of your conception of the good; finally, you must possess abilities of argumentation to generate and critique arguments and counterarguments so you can judge whether to revise your views about the good. Without such psychological capacities, one would be unable to possess the second moral power. Since, as discussed later, adolescents have all those abilities, they can therefore revise their conception of the good.

The ability rationally to pursue that conception of the good is provided by empirical reasoning, argumentation and decision-making rationality. Empirical reasoning is necessary to assess for yourself the best means to your ends and argumentation, which includes the ability to follow and critique arguments, is necessary to assess the advice of others, e.g. doctors, lawyers, etc., who might provide advice on how best to achieve your ends. Decision-making rationality is also necessary 'rationally to pursue' your conception of the good, since individuals need it to avoid decision-making fallacies that could otherwise frustrate their actions. By having the same abilities of empirical reasoning, argumentation and decision-making as adults, adolescents have an equal ability rationally to pursue their conception of the good.

Finally, individuals need the capacity to specify 'an ordered family of final ends and aims'. ${ }^{28}$ The ability to order, weigh up and trade-off different goals and values requires the ability to make 'preference judgments' (a component of decision-making rationality), which consist in weighing up and trading-off different preferences. However, since it is not merely preferences that

Rawls, Justice as Fairness: A Restatement, p. 19 
must be weighed in a conception of the good but also normative values, weighing ends also requires moral reasoning abilities. Complex moral reasoning, which involves balancing personal goals, social norms and moral values, is important so that individuals can coordinate different normative values within their own thinking. And as will be discussed later, adolescents and adults have the same levels of moral reasoning and decision-making abilities.

The first moral power, as we are understanding it here, is the capacity to understand, apply, and act from moral principles and principles of justice. The ability to understand those principles is given by a level of development in prosocial moral reasoning at least beyond hedonistic and direct-reciprocity reasoning; and, for complex dilemmas, development in complex moral reasoning. In additional to moral reasoning, the first moral power requires the other abilities necessary for 'rational pursuit' described in the above discussion of the second moral power (empirical reasoning, argumentation, decision-making).

The above outlines how the two moral powers correspond to various aspects of cognitive psychology. Therefore, in demonstrating that adolescents possess equivalent levels of the five key psychological capacities, we will have demonstrated that adolescents possess the two moral powers and therefore (via the arguments of Section 2) that they have a pro tanto right to vote. Let's now investigate each of those five psychological capacities in turn: logical/syllogistic reasoning, empirical reasoning, decision-making, argumentation and moral reasoning.

\section{Logical Reasoning}

\subsection{Definition}

Logical reasoning includes three core abilities: (1) to understand the rules of logic and inference; (2) to understand the concept of 'validity' as distinct from 'truth' and to follow deductive arguments and assess their validity. And the ability not only to understand and follow given logical inferences but (3) to draw inferences oneself from given premises. This includes being able to solve both determinate and indeterminate syllogisms. ${ }^{29}$ Determinate syllogisms are syllogisms in which the conclusion follows from the premises with logical necessity. Indeterminate syllogisms, by contrast, involve conclusions that are perhaps suggested by the premises, but do not follow as a matter of necessity. Logical reasoning, therefore, covers the ability to understand and apply the rules of logic.

\subsection{Normative Significance}

Logical reasoning abilities are at the heart of philosophical accounts of humans as rational beings. Logical rea-

29. Paul A. Klaczynski, Mary J. Schuneman, and David B. Daniel, “Theories of Conditional Reasoning: A Developmental Examination of Competing Hypotheses," Developmental Psychology 40, no. 4 (2004), pp. 559-71. soning is important for forming beliefs, making evaluative judgments, means-ends reasoning, justifying one's beliefs, and forming and following arguments and counterarguments. Indeed, logical reasoning is a prerequisite for all the accounts of autonomy mentioned earlier. The second moral power requires that people be able to have a 'rational plan of life'. But someone unable to reason logically cannot have a 'rational' plan of life properly speaking, since their plans do not flow from the exercise of reason. ${ }^{30}$ Similarly, they cannot reason morally (a requirement of the first moral power), form logically consistent preferences (a requirement of the second moral power), or form practical syllogisms to make rational decisions or assess evidence (required by both moral powers). Logical/syllogistic reasoning is therefore a major component of the two moral powers and is a prerequisite for all other components of rationality.

Second, logical reasoning abilities protect individuals (morally) from certain kinds of paternalism. Respect for an individual's ability to reason means not interfering with the decisions the individual makes on the basis of that ability. Interference would be illegitimate. However, if they lack that ability, then we no longer have the same reason to respect their right to self-government and so no longer have the same reason to include them formally in decision-making processes that govern them. Yet if an individual possesses this ability for self-government (i.e. possesses the two moral powers), then respect means, generally speaking, allowing individuals to make decisions about themselves; and when society as a whole governs over the individual, they are bound to include that individual in the decision-making process. Therefore, logical reasoning helps to ground rights to inclusion in the political process.

\subsection{Empirical Findings}

Let's take each of the three components of logical reasoning in turn. First, in understanding validity as distinct from truth, adolescents and adults make similar errors in deductive reasoning when the premises are counterfactual. ${ }^{31}$ Moshman and Franks (1986) investigated whether participants in their study could recognise validity as distinct from truth. In the initial experiments, $45 \%$ of 12 - to 13 -year-olds and $85 \%$ of college students used validity as a basis for distinguishing different arguments. In later experiments, the experimenters explained the concept of validity to the participants. 12- to 13-year-olds could then understand and apply the concept of validity just as well as college students; indeed, their results were almost indistinguishable. ${ }^{32}$

30. Though they may, by chance, have the appearance of rationality.

31. Henry Markovits and Robert Vachon, "Reasoning with Contrary-toFact Propositions," Journal of Experimental Child Psychology 47, no. 3 (1989), pp. 398-412; Deanna Kuhn and Robert S. Siegler, Handbook of Child Psychology. Volume 2, Cognition, Perception, and Language, 6th ed. (Hoboken, NJ: John Wiley, 2006), p. 962.

32. David Moshman and Bridget A. Franks, "Development of the Concept of Inferential Validity," Child Development 57, no. 1 (1986), pp. 153-65; Moshman, Adolescent Psychological Development: Rationality, Morality, and Identity, p. 15. 
Second, we can examine the ability to solve determinate and indeterminate syllogisms. When solving problems involving the most common determinate syllogisms (e.g. modus ponens, modus tollens), performance is very good by middle to late childhood at $75 \%$ accuracy, and is near ceiling level by adolescence. ${ }^{33}$ For the most difficult determinate syllogisms, there is 'no clear developmental change' from the age of 8 onwards, with performance 'remaining poor through adulthood'. ${ }^{34}$ Therefore, there is no difference in the inferential abilities of adults and adolescents in solving determinate syllogisms.

In studies investigating the ability to solve indeterminate syllogisms, individuals are provided with premises that involve denying the antecedent or affirming the consequent. They are then asked whether they can infer a definite conclusion. ${ }^{35}$ An argument that affirms the consequent provides the premises:

$$
\begin{aligned}
& \text { if } p \text { then } q \\
& q
\end{aligned}
$$

This argument 'invites' us (invalidly) to infer $p$ as a conclusion. An argument that denies the antecedent provides the premises:

\section{if $p$ then $q$ not $p$}

This argument 'invites' us to conclude (invalidly) that 'not $q$ '. The correct answer is that we cannot infer a definite conclusion from either syllogism. ${ }^{36}$ In general, mistakes in solving indeterminate syllogisms decrease with age. In their landmark study, Klaczynski et al. (2004) found correct indeterminate inferences were apparent only in the adolescent (12-14) and adult groups, with a small ability gap between those groups. ${ }^{37}$

To summarise, young adolescents (12-14) are equivalent to adults in their understandings of validity and their ability to solve determinate syllogisms, but are slightly behind adults in their ability to solve indeterminate syllogisms. Older adolescents (15-16), however, have the same or similar logical abilities as adults. ${ }^{38}$

33. Kuhn and Siegler, Handbook of Child Psychology. Volume 2, Cognition, Perception, and Language, p. 961. Also Klaczynski, Schuneman, and Daniel, "Theories of Conditional Reasoning: A Developmental Examination of Competing Hypotheses."

34. Kuhn and Siegler, Handbook of Child Psychology. Volume 2, Cognition, Perception, and Language, p. 961; Klaczynski, Schuneman, and Daniel, "Theories of Conditional Reasoning: A Developmental Examination of Competing Hypotheses."

35. Robert B. Ricco, "The Development of Reasoning," in Handbook of Child Psychology and Developmental Science. Volume 2, Cognitive Processes, ed. Lynn S. Liben, et al. (Hoboken, NJ: John Wiley, 2015), pp. 525-26.

36. Ibid., pp. 525-27

37. Klaczynski, Schuneman, and Daniel, "Theories of Conditional Reasoning: A Developmental Examination of Competing Hypotheses," pp. 566 and 533.

38. Moshman, Adolescent Psychological Development: Rationality, Morality, and Identity, p. 40.

\section{Empirical Reasoning}

\subsection{Definition}

Under 'empirical reasoning' I class together the technically separate cognitive abilities of inductive/causal reasoning and scientific reasoning/hypothesis testing.

Inductive/causal reasoning consists of three key components. (1) The ability to identify (potential) causes in multivariable contexts and understand the importance of isolating variables when making causal inferences. (2) The ability to coordinate prior expectations with new information. People who lack sufficient control over the interaction of theory and evidence in their thinking might ignore new evidence and base inferences on their prior theory; distort evidence; or selectively recognise only the data that fits their theory.$^{39}$ Finally, inductive/ causal reasoning includes (3) the ability to make justified inductive inferences.

Scientific thinking is the ability to form basic experiments to test one's hypotheses. ${ }^{40}$ It involves the ability to solve problems across four phases: (i) the inquiry phase, where 'the goals of the activity are formulated' and 'the questions to be asked are identified'. ${ }^{41}$ The various possible investigative strategies formed in the inquiry phase include, in increasing order of sophistication: just generate experimental outcomes; see what makes a difference in outcomes; investigate the effect of specific variables on outcomes. (ii) Analysis: one identifies relevant evidence and analyses it. ${ }^{42}$ (iii) Inference strategies involve applying mental operations to the evidence to derive conclusions from that evidence. ${ }^{43}$ Inferential strategies range in adequacy from making unsupported claims without processing the evidence to skilled coordination of theory and evidence. ${ }^{44}$ (iv) $\mathrm{Argu}$ ment, which I discuss in Section 7, involves the ability to construct arguments and deal with counterarguments. With argumentation abilities, one can explain and justify the claims produced by the earlier phases of scientific thinking. Hypothesis testing/scientific thinking, in sum, refers to the ability to form relevant, testable hypotheses; understand logically how to test those hypotheses; run valid tests to get relevant data; and draw valid inferences from that data.

39. Kuhn and Siegler, Handbook of Child Psychology. Volume 2, Cognition, Perception, and Language, p. 965; Deanna Kuhn, "Children and Adults as Intuitive Scientists," Psychological Review 96, no. 4 (Oct 1989), pp. 674-89; Ricco, “The Development of Reasoning," p. 556.

40. Deanna Kuhn, "What Is Scientific Thinking and How Does It Develop?," in The Wiley-Blackwell Handbook of Childhood Cognitive Development, ed. Usha Goswami, 2nd ed. (Chichester: John Wiley, 2010); Bärbel Inhelder and Jean Piaget, The Growth of Logical Thinking from Childhood to Adolescence: An Essay on the Construction of Formal Operational Structures, trans. Anne Parsons and Stanley Milgram (London: Routledge and Kegan Paul, 1958).

41. Kuhn, "What Is Scientific Thinking and How Does It Develop?," p. 505.

42. Ibid., p. 506.

43. Ibid; Kuhn and Siegler, Handbook of Child Psychology. Volume 2, Cognition, Perception, and Language, p. 973.

44. Kuhn, "What Is Scientific Thinking and How Does It Develop?," p. 507. 


\subsection{Normative Significance}

Normatively, empirical reasoning is important for rights that presuppose an ability to make judgments about the world. Most significantly, it enables individuals to apply means-ends reasoning.

Theoretically, empirical reasoning forms part of both moral powers. For the second moral power - the capacity to have, to revise, and rationally to pursue a conception of the good - it provides the ability 'rationally to pursue' that conception of the good. This is because 'rational pursuit' involves taking the best means to your ends, and means-ends reasoning requires empirical judgments. For example, if your stated goal is improved fitness, you need to work out empirically whether sitting on a sofa, eating cake or jogging will achieve that goal. Therefore, empirical reasoning is necessary for the two moral powers. Empirical reasoning has a second importance: it facilitates the formation of a conception of the good, understood as a family of ordered final ends, because it helps the individual to learn what ends are technically compatible and incompatible. For example, we might reason, empirically, whether it is possible to (a) enjoy rich foods, (b) stay slim and (c) avoid exercise. If we (alas) reason that these are incompatible, we are forced to rank and order these goals. For the first moral power, empirical reasoning is required for the meansends reasoning needed to 'apply' principles of justice and, just as it facilitates trading-off personal preferences and goals, it facilitates trading-off and weighing moral values. Empirical reasoning, therefore, is a key component of each moral power.

Practically, means-ends reasoning is a prerequisite for the franchise on most accounts of voting, since most accounts require voters to understand/critique/propose practical policies. Means-ends reasoning may be unnecessary for the franchise under some theories: certain economistic theories of voting, for example, only ask voters to reveal their ultimate preferences when voting ${ }^{45}$ other theories ask voters to reason exclusively on the moral plane, leaving means-ends judgments to technocrats. ${ }^{46}$ Autonomy-based accounts, however, may rule out such technocratic forms of government as disrespecting voters' capacity to reason empirically. Whatever may be required in the ideal democratic system, in the real world politics demands that voters assess practical policies and their likely effects. Since we must assess policies when voting, and since assessing policies requires reasoning empirically about their effects, empirical reasoning is necessary for voting.

\subsection{Empirical Findings}

Let's first examine development in scientific reasoning and then development in inductive reasoning.

As discussed previously, scientific reasoning breaks down into four phases, each with its own modes of reasoning.

In the inquiry phase of investigation, preadolescent children tend to apply less sophisticated strategies than adults and adolescents. The most sophisticated investigation strategy is the 'falsification strategy', in which one formulates a hypothesis and attempts to disprove it. But when comparing adolescents and adults, it seems that they are both generally (in)capable of reasoning effectively in the inquire phase of reasoning: most adults and most adolescents fail to apply the falsification strategy. ${ }^{47}$

With respect to analysis and inference, people in middle childhood (8-11) sometimes appear quite ready to interpret multiple variables as causing an outcome based on a single co-occurrence of the variable and the outcome, and empirical observations are used more to illustrate theories than test them. ${ }^{48}$ Despite these weaknesses, there is only modest improvement between middle childhood (8-11) and early adulthood, with 'far from ideal' performance by adults. Among 11- to 12-yearolds, the proportion of beliefs in a test scenario based on evidence-based inferences (rather than erroneous theory-based inferences) was about $25 \%$, compared with roughly $50 \%$ for non-college young adults. Following an evidence-focus probe (where testers ask participants questions like, 'do these results tell you anything about whether X has an effect?') these percentages increased to $60 \%$ and $80 \%$, respectively. ${ }^{49}$ And when interpreting some kinds of evidence, adults are just as likely to exhibit certain kinds of bias as 11- to 12 -year-olds. ${ }^{50} \mathrm{Kuhn}$ et al. (1995) conclude that, for scientific reasoning, there is only 'some improvement in the years between middle childhood and early adulthood': individual variance is high and age-related improvements are small. ${ }^{51}$ It seems, therefore, that there is only a minimal difference between younger adolescents (12-14) and adults in the ability to reason scientifically.

Now turning to inductive/causal reasoning, we investigate the three components separately. (i) Inductive inference: we have already shown that adolescents and adults have roughly the same ability to make inductive inferences. (ii) Regarding the ability to identify and isolate variables in experiments, and understand why doing so is
45. E.g. Joseph A. Schumpeter, Capitalism, Socialism, and Democracy (Lanham, MD: Start Publishing, 2012); Kenneth Joseph Arrow, Social Choice and Individual Values, 3rd ed. (New Haven, CT; London: Yale University Press, 2012).

46. Max Weber, "Bureaucracy," in From Max Weber: Essays in Sociology, ed. Hans Gerth and C. Wright Mills (Oxford; New York: Routledge, 2009a); "Politics as a Vocation," in From Max Weber: Essays in Sociology, ed. Hans Gerth and C. Wright Mills (Oxford; New York: Routledge, 2009b).
47. Moshman, Adolescent Psychological Development: Rationality, Morality, and Identity, p. 17; Jonathan St B. T. Evans, Bias in Human Reasoning: Causes and Consequences (London: Erlbaum, 1989). Also Deanna Kuhn et al., "Strategies of Knowledge Acquisition," Monographs of the Society for Research in Child Development 60, no. 4 (1995), pp. 1-127.

48. Kuhn, "What Is Scientific Thinking and How Does It Develop?," esp. p. 508.

49. Kuhn and Siegler, Handbook of Child Psychology. Volume 2, Cognition, Perception, and Language, p. 966.

50. Ibid.

51. Ibid. 
important, we have already shown that adolescents fully possess this ability. For the avoidance of doubt:

adolescents have the ability to form hypotheses in advance and to perform experiments that isolate variables. ${ }^{52}$

(iii) Coordinating theory and evidence: individuals are considered incapable of adequate coordination if they are more likely to interpret evidence as valid when it is consistent with their previously held theories, and/or if they interpret identical evidence differently as a function of its consistency with their prior theory. In fact, people of all ages ignore and distort evidence that is discrepant with their prior beliefs. ${ }^{53}$ And by adolescence, the rates of bias are identical to those of adults. ${ }^{54}$ Indeed, as aggregate groups, adults have abilities equivalent, not only to adolescents, but also to people towards the end of middle childhood. ${ }^{55}$

To summarise, there is no significant difference between adults and adolescents in their cognitive capabilities for empirical reasoning. This means we must respect adolescents' empirical beliefs and cannot deny them the vote on the grounds they reason differently from older citizens or hold different empirical beliefs than older citizens.

\section{Decision-Making}

\subsection{Definition}

Decision-making rationality has two main components: the ability to make sound preference judgments and the ability to make sound decision judgments. Preference judgments involve the abilities to (i) render one's preferences consistent; ${ }^{56}$ and (ii) select appropriate choice strategies when applying preferences to concrete choices (e.g. deciding how to weight different preferences). ${ }^{57}$ Decision judgments are about making decisions in accordance with sound decision-making principles and

52. Fred Danner, "Cognitive Development in Adolescence," in The Adolescent as Decision-Maker: Applications to Development and Education, ed. Fred Danner and Judith Worell (San Diego; London: Academic Press, 1989), pp. xii, 320 pages. Also Moshman, Adolescent Psychological Development: Rationality, Morality, and Identity, fn 38.

53. Richard Lehrer and Leona Schauble, "The Development of Scientific Thinking," in Handbook of Child Psychology and Developmental Science. Volume 2, Cognitive Processes, ed. Lynn S. Liben, et al. (Hoboken, N.J.: John Wiley, 2015), p. 694.

54. Kuhn and Siegler, Handbook of Child Psychology. Volume 2, Cognition, Perception, and Language, p. 971. See also Ricco, “The Development of Reasoning," p. 536.

55. Kuhn and Siegler, Handbook of Child Psychology. Volume 2, Cognition, Perception, and Language, p. 966; Kuhn et al., "Strategies of Knowledge Acquisition"; Lehrer and Schauble, "The Development of Scientific Thinking," p. 695.

56. See John Von Neumann and Oskar Morgenstern, Theory of Games and Economic Behavior (Princeton, NJ; Oxford: Princeton University Press, 2004).

57. Yoella Bereby-Meyer, Avi Assor, and Idit Katz, "Children's Choice Strategies: The Effects of Age and Task Demands," Cognitive Development 19 , no. 1 (2004), pp. 127-46. avoiding decision fallacies, such as hindsight bias; ${ }^{58}$ contingency bias $;{ }^{59}$ outcome bias $;{ }^{60}$ the gamblers' fallacy; and the sunk-cost fallacy.

\subsection{Normative Significance}

Theoretically, decision judgments and preference judgments are each important for the two moral powers. Preference judgments are important for possessing a 'conception of the good'. A conception of the good (required for the second moral power) specifies 'an ordered family of final ends and aims'. Since our preferences constitute some of our final ends and aims, and since preference judgments are necessary to 'order' those final ends, the ability to make preference judgments is necessary for the second moral power. However, the ability to make preference judgments is not sufficient for the individual to be able to reason about their preferences morally. Therefore, decision-making rationality does not entail a full-blown ability to hold, form and revise a conception of the good, although it is necessary for those abilities.

Second, decision judgments are important for the ability 'rationally to pursue' a conception of the good. 'Rational pursuit' of a goal involves both choosing the best means to your ends and actually applying that reasoning in a decision. After all, what is the use of means-ends reasoning if you cannot apply it to any concrete decision? Decision-making fallacies confound this application and lead us to make irrational and suboptimal decisions. Decision-making rationality enables us 'rationally to pursue' our conceptions of the good by helping us avoid those decision-making fallacies. By the same reasoning, decision-making rationality is necessary to apply moral principles in our decisions and is therefore necessary for the first moral power.

Practically, preference judgments are important for voting: someone who cannot render their preferences rational cannot have their preferences taken into account. When someone completely lacks the ability to render their preferences rational - even when their irrationality is pointed out to them - there is not even a prima facie reason to take their declared preferences into account. It is not clear what such a person is really expressing when declaring inconsistent/irrational 'preferences'. It is unclear whether such a person really has any preferences; and, even if they do, they seem unable to express or represent those underlying preferences. Decision-making rationality is therefore important for any right, such as voting, which presupposes that someone knows, and can express, their preferences.

Therefore, decision-making ability is important for the right to vote because (i) it is a prerequisite for rights that require having and expressing at least minimally coher-

58. Daniel Kahneman and Amos Tversky, "On the Reality of Cognitive Illusions," Psychological Review 103, no. 3 (1996), pp. 582-91.

59. Suzanne C. Thompson, "Illusions of Control: How We Overestimate Our Personal Influence," Current Directions in Psychological Science 8, no. 6 (1999), pp. 187-90.

60. Francesca Gino, Don A. Moore, and Max H. Bazerman, No Harm, No Foul: The Outcome Bias in Ethical Judgments (Harvard: Harvard Business School, 2009). 
ent preferences; (ii) preference judgments are important for holding a conception of the good; (iii) decision judgments are required for the moral powers, so we can rationally apply our goals and principles.

\subsection{Empirical Findings}

Capon and Kuhn (1980) compared adults with four age groups (kindergarten, fourth grade, eighth grade and college). Subjects rated a product along different dimensions and said how important those different dimensions were. Subjects of all ages were likely to possess and express preferences along each individual dimension. The researchers then asked them to rank the products. Both adolescents and adults could integrate their preferences from two or more dimensions; younger children, however, tended to make product judgments on the basis of a single, constant dimension, ignoring other dimensions over which they had expressed preferences. Similarly, Bereby-Meyer et al. (2004) investigated the choice strategies participants employed when applying their preferences to choosing a product. 4- to 6-yearolds base their choices mainly on the perceptual features of a product. 8- to 9-year-olds could form more complex preferences, but when applying them to choices, they tended to use a lexicographic strategy, that is, only take the single most important attribute into consideration in their ranking. 9- to 13-year-olds could choose correctly between two alternatives (each with three attributes) by using the lexicographic and equal-weighting strategies flexibly. Generally, 12- to 13-year-olds could make preference judgments as well as adults.

There are a number of studies comparing adolescent and adult decision-making directly. ${ }^{61}$ When making decisions,

adolescents do not differ from adults in their competence, whether determined by their understanding of alternatives, the rationality of their reasoning, or the reasonableness of their choices. ${ }^{62}$

In studies testing decision-making fallacies, 'older teens did not perform substantially worse, if at all inferior, to adults'. ${ }^{63}$ And, in general, the picture is of 'modest improvement' through the teen years, with adults reaching only a 'very modest' level of decision-making rationality, with the average adult at least as likely (and often much more likely) to make incorrect judgments as cor-

61. See Paul A. Klaczynski, "Analytic and Heuristic Processing Influences on Adolescent Reasoning and Decision-Making," Child Development 72 , no. 3 (2001a), pp. 844-61 and "Framing Effects on Adolescent Task Representations, Analytic and Heuristic Processing, and Decision Making: Implications for the Normative/Descriptive Gap," Journal of Applied Developmental Psychology 22, no. 3 (2001b), pp. 289-309.

62. Gary B. Melton, "Are Adolescents People? Problems of Liberty, Entitlement, and Responsibility," in The Adolescent as Decision-Maker: Applications to Development and Education, ed. Fred Danner and Judith Worell (San Diego; London: Academic Press, 1989), p. 282. See also Gerald P. Koocher, Gary B. Melton, and Michael J. Saks, Children's Competence to Consent (New York: Plenum, 1983).

63. Kuhn and Siegler, Handbook of Child Psychology. Volume 2, Cognition, Perception, and Language, p. 977. rect ones in test scenarios. ${ }^{64}$ Indeed, one survey of the material on competence of children suggested that the majority of people at 14 had similar decision-making capacities as adults. ${ }^{65}$ Therefore, since 12- to 16-yearolds are about as likely to avoid decision-making errors as adults, we cannot treat adolescents differently on the basis of their decision-making rationality.

\section{Argumentation}

\subsection{Definition}

Broadly, argumentation skills are of two types, only one of which is a component of autonomy. The first, which we are interested in, is 'argument construction', which covers the cognitive abilities of producing justifications and counterarguments, and rebutting counterarguments. The second is 'argumentative discourse' or 'discourse strategies', which is about engaging in a dialogue in social contexts and about strategies to force concessions from opponents or challenge their key premises. ${ }^{66}$ This second set of skills is not about constructing an argument, but about competitive debating and negotiation. While (as discussed later) mid and late adolescents possess argument construction abilities which are similar to adults', they lag behind in social discourse strategies. Specifically, in social discursive (or debate) scenarios, mid-adolescents are not as good as adults at selecting strategies to challenge opponents or defend their own position, at portraying the merits of opponents' positions, or at coordinating multiple perspectives in an argument. ${ }^{67}$

Why are discourse strategies less normatively relevant to us here? For autonomy, as set out in Sections 2 and 3, individuals must be able to produce arguments (understood as chains of reasoning rather than performative debates) to generate and critique their conceptions of the good, conceptions of justice, and plans to pursue them. This basic ability to form autonomous plans does not require the debating skills, verbal dexterity and argumentative strategy required for 'argumentative/ social discourse'. While debating may help individuals formulate their autonomous goals, it is not a core component of autonomy itself. Sure, on epistocratic or competence-based approaches to democracy, debating abilities may help improve the quality of democratic discourse. Then again, since debating skills are often linked to formal education, requiring that citizens be good

64. Ibid

65. Schmidt and Reppucco, "Children's Rights and Capacities," p. 160.

66. See Mark K. Felton, "The Development of Discourse Strategies in Adolescent Argumentation," Cognitive Development 19, no. 1 (2004), pp. 35-37; Deanna Kuhn and Wadiya Udell, "The Development of Argument Skills," Child Development 74, no. 5 (2003), p. 1245.

67. I thank an anonymous reviewer for pressing this point. See Felton, "The Development of Discourse Strategies in Adolescent Argumentation," pp. 35-52; Deanna Kuhn and Wadiya Udell, "Coordinating Own and Other Perspectives in Argument," Thinking \& Reasoning 13, no. 2 (2007), pp. 90-104; Kuhn and Udell, "The Development of Argument Skills." 
debaters to have the vote may reduce the diversity of voices and hence the quality of democratic decisionmaking. In any case, the autonomy approach is less concerned with the quality of show debates and discussions. As such, so long as the individual can construct their own arguments to form a conception of the good, assess how to achieve it, etc. they are autonomous in the correct way. Therefore, the abilities of 'argumentative discourse' are less relevant for the autonomy account laid out here.

The psychological capacities that we are interested in are the skills of 'argument construction'. These skills (which form the last phase of 'scientific reasoning' discussed previously) include generating and evaluating reasoned argument. ${ }^{68}$ (i) Argument generation involves (a) offering valid supporting arguments for one's opinions; and (b) envisioning and critiquing counterarguments to those opinions. (ii) Argument evaluation involves assessing the strength or soundness of arguments and counterarguments, and, importantly, being able to do this regardless of whether you independently disagree with the conclusion.

\subsection{Normative Significance}

There are two main ways argument construction is relevant for the franchise.

First, as mentioned in the previous sub-section, skills of argumentation are important for the ability to form reasoned views of the right and the good, and how to pursue them, by forming arguments for those positions, probing the weaknesses of those positions and considering alternative positions.

Second, argumentative ability is important for individuals to make decisions in scenarios where they rely on expert advice. Means-ends judgments are required for both moral powers. When we cannot make means-ends judgments ourselves, we must rely on the judgments of others. But to understand those judgments fully, and to weigh the reasons given for and against various options, we must be able to evaluate those expert judgments and opposing arguments. Such abilities facilitate the informed consent required to preserve autonomy. The argument for the normative importance of argumentative abilities in this sphere runs as follows:

i. To be fully autonomous, we must understand (the reasons for and against) the decisions we make (i.e. our decisions must be based on informed consent).

ii. Many decisions require specialised knowledge to understand the options, and this knowledge is (ordinarily) accessible only via expert advice.

iii. For that advice to help us understand certain options, we must be able to understand and assess the reasons for/against those options (i.e. have argumentative capabilities).

Therefore:

68. Kuhn and Siegler, Handbook of Child Psychology. Volume 2, Cognition, Perception, and Language, p. 978. For discussion of different frameworks, see Lehrer and Schauble, "The Development of Scientific Thinking," pp. 700-4. iv. To be fully autonomous when making specialised decisions, individuals require argumentative capabilities.

Premise (i) is true since, to make an autonomous decision, 'one's choice must be real; [thus] one must have at least a certain minimum education and information'. ${ }^{69}$ If one lacks key information, then this acts as a hindrance to meaningful choice. ${ }^{70} \mathrm{We}$ do, for example, take (unwilful, non-negligent) ignorance as a defence for many crimes, ${ }^{71}$ and doctors are required to provide patients with information to help the patient make a decision. ${ }^{72}$ Premise (ii) is empirically true of many of the decisions we make in the political sphere, which depend on policy expertise or economic or scientific expertise etc. I also take (iii) to be true. When giving advice, experts usually provide us with certain options (even if one option is 'do nothing') and give reasons for and against each option; thus, giving advice involves providing reasons. Argumentative ability includes the ability to follow and critique those reasons. Therefore, to understand the advice of experts, we need argumentative abilities. Note that the capabilities in (iii) do not require strategic discourse, since when we read expert opinions or take expert advice, we are rarely in an adversarial scenario where we are trying to 'win' the argument. We merely need cognitive abilities to follow and critique those arguments. From (i) to (iii) it follows that, to be fully autonomous when making specialised decisions, individuals must be able to understand, follow and evaluate the advice (arguments) of others and hence require some level of argumentative ability.

If an individual lacks argumentative capabilities, and therefore cannot comprehend or assess the advice they are being given, then we would doubt their ability to make an informed decision. And if an individual is unable to make informed decisions, then we are not required, out of respect for autonomy, to respect their decisions, whether personal or political. Note that the concern here is not that individuals actually do possess that knowledge, but rather that they possess the ability (and opportunity) to gather that knowledge. On the flip side, if they possess this capacity and they can make autonomous and informed decisions, then we must respect their decisions out of respect for their autonomy.

\subsection{Empirical Findings}

As with the other stages of scientific reasoning described earlier, age is not an effective proxy at measuring development in persuasive and perspective-taking abilities; there is wide variability in individual abilities. ${ }^{73}$ Argu-

69. Griffin, On Human Rights, p. 33.

70. Tom L. Beauchamp and James F. Childress, Principles of Biomedical Ethics, 7th ed. (New York: Oxford University Press, 2013), pp. 120-21.

71. E.g. R v. G \& R [2003] 3 WLR House of Lords.

72. Jonathan Herring, Medical Law and Ethics, 5th ed. (Oxford: Oxford University Press, 2014), pp. 165-72.

73. Ruth Anne Clark and Jesse G. Delia, "The Development of Functional Persuasive Skills in Childhood and Early Adolescence," Child Development 47, no. 4 (1976), p. 1013. 
mentation, as explained earlier, is composed of (i) argument generation, which includes generating supporting arguments and considering counter-arguments; and (ii) argument evaluation. Let's take each in turn.

(1) Generation of supporting arguments. There is some slight difference between younger teenagers and adults here. ' $[\mathrm{O}] \mathrm{n}$ average about one-third of a teen sample' could offer 'a valid supporting argument for their claim $[\mathrm{s}]$... a percentage that increased only very modestly to near one half among adults' ${ }^{74}$ Therefore, there is some small difference between adults and young adolescents in generating supporting arguments. However, this difference in ability is eliminated by later adolescence and, anyway, chronological age between 12 and 60 is not a strong predictor of this skill. ${ }^{75}$

(2) Consideration of counterarguments. In some studies on the topic, it was found that young adolescents concentrate their efforts on exposition of their own claims to the neglect of attending to their opponent's claims. Kuhn and Udell (2007) found that when adults and adolescents are asked to write arguments in favour of their position, about half of adults will attend to rebutting potential counterarguments, whereas a little under a third of 12- to 14-year-olds will do the same. ${ }^{76}$ However, when their ability to consider counterarguments is tested directly, they are at near ceiling performance, meaning that an 'inability to generate arguments against an opposition position cannot be regarded as a major contributor' to their lower tendency to generate counterarguments. ${ }^{77}$ They can 'attend to the other's argument ... when explicitly instructed to do so'. ${ }^{78}$ Therefore, it seems that the differences between young teens and adults are explained by differences in argumentative strategy rather than in argument construction. Thus, adolescents do have the ability to consider counterarguments, even if, as a matter of strategic judgment, they often do not. Since we care about the possession of capabilities (rather than the second-order inclination to deploy them), it is possessing these first-order capabilities that matters for their autonomy. And indeed, contrary to their earlier results, Kuhn and Siegler (2006) find that young teens (12-14) and adults are equally likely to address both sides of the argument in an argumentative scenario. ${ }^{79}$ Taking (1) and (2) together, overall:

74. Kuhn and Siegler, Handbook of Child Psychology. Volume 2, Cognition, Perception, and Language, p. 979.

75. Ibid.

76. Kuhn and Udell, "Coordinating Own and Other Perspectives in Argument," p. 100.

77. Ibid., pp. 100-1

78. Deanna Kuhn et al., "Arguing on the Computer: A Microgenetic Study of Developing Argument Skills in a Computer-Supported Environment," Child Development 79, no. 5 (2008), pp. 1310-28, 1311. Also Kuhn and Udell, "Coordinating Own and Other Perspectives in Argument."

79. Kuhn and Siegler, Handbook of Child Psychology. Volume 2, Cognition, Perception, and Language, p. 979. See also Deanna Kuhn, Victoria Shaw, and Mark Felton, "Effects of Dyadic Interaction on Argumentive Reasoning," Cognition and Instruction 15, no. 3 (1997), pp. 287-315; Mark Felton and Deanna Kuhn, "The Development of Argumentive Discourse Skill," Discourse Processes 32, no. 2-3 (2001), pp. 135-53. the available research indicates only slight improvement during the adolescent years [from age 12] in the ability to produce sound arguments. ${ }^{80}$

(3) Argument evaluation. For this, psychologists measure the bias towards those arguments whose conclusions you already agree with by measuring your tendency to miss deliberately planted mistakes in those arguments. Both adolescents and adults, 'exhibited a positive bias towards studies that portrayed their group favourably', and 'the extent of this bias did not diminish with age'. Indeed, 'on one indicator it in fact increased' with age ${ }^{81}$ Thus, adolescents do not lag behind adults in their ability to evaluate arguments. ${ }^{82}$

There is no difference in the argument construction abilities of adults and adolescents, and adolescents lag behind adults only in argumentative strategy. It also seems that many such skills can be improved through education and training. ${ }^{83}$ Therefore, we cannot appeal to argumentative construction abilities as a basis for granting different rights to older adolescents (14-16) and adults.

\section{Moral Reasoning}

In this section, I examine development in moral reasoning. Moral reasoning is important for the two moral powers. The ability to reason in moral terms, and be motivated by that reasoning, implies and constitutes the first moral power, that is, the capacity to understand, to apply and to act from moral principles and principles of justice. Moral reasoning is also important for the second moral power, since the ability to reason morally also implies an ability to reason about the good. This can supply the last few pieces of the second moral power (the capacity for a conception of the good), namely, it supplies the ability to 'have' a conception of the good and a full ability to 'revise' it. The ability to have a conception of the good requires the ability to understand and internalise norms and principles about the good. An ability to revise a conception of the good requires the ability to reason in evaluative and normative terms, abilities that correspond to moral reasoning.

I first examine development in prosocial moral reasoning and then complex moral reasoning (which involves balancing social and personal goals with moral considerations). In each case, the results show that adolescents

80. Kuhn and Siegler, Handbook of Child Psychology. Volume 2, Cognition, Perception, and Language, p. 979.

81. Ibid., p. 980

82. See also Deanna Kuhn, "How Do People Know?," Psychological Science 12, no. 1 (2001), pp. 1-8, 5

83. Kuhn, "What Is Scientific Thinking and How Does It Develop?," p. 512; Kuhn and Siegler, Handbook of Child Psychology. Volume 2, Cognition, Perception, and Language, pp. 981-82; Marion Goldstein, Amanda Crowell, and Deanna Kuhn, "What Constitutes Skilled Argumentation and How Does It Develop?," Informal Logic 29, no. 4 (2010), p. 379 
can reason morally in nuanced and sophisticated ways, and to the same level as adults.

\subsection{Prosocial Reasoning}

Prosocial moral reasoning is:

reasoning about moral dilemmas in which one person's needs or desires conflict with those of others in a context in which the role of prohibitions, authorities' dictates, and formal obligations is minimal. ${ }^{84}$

Prosocial moral reasoning is not therefore looking at obedience to law or deference to authority but purely at interpersonal moral conflicts. ${ }^{85}$ Empirically, it seems that from the age of 12 individuals reason using abstract moral principles and can reason in nuanced ways about distributive fairness, incorporating factors such as desert, talent, advantage and disadvantage. ${ }^{86}$ These results are confirmed in a large, long-running longitudinal study into the development of prosocial moral reasoning in individuals aged 6-20 run by Eisenberg et al. ${ }^{87}$ Interestingly, hedonistic (i.e. self-interested), direct-reciprocity (you scratch my back, I'll scratch yours) and approval-oriented (concern with social approval and acceptance) modes of moral reasoning, all of which declined through adolescence, stopped declining, and even increased slightly, in early adulthood. Overall, the results show that individuals from early adolescence can use the range of moral concepts and principles in their prosocial moral reasoning that are available to adults. And, indeed, the results suggest that adolescents are more willing to use more of those other-regarding moral concepts than individuals in early adulthood, when people become more concerned with social perceptions and social success relative to other moral concerns than at younger ages. ${ }^{88}$

Indeed, even in tests of strong moral dilemmas that, unlike the prosocial scenarios, involve legal obligations and dictates of authority (e.g. can you steal medicine to save your sick wife?), adolescents and adults are at the same level of moral reasoning. ${ }^{89}$ Preadolescent children often struggle in such scenarios and default to mere obedience to authority or to self-interested reasoning about the need to avoid punishment. ${ }^{90}$ Such reasoning is especially common in young children, although adults can

84. Nancy Eisenberg et al., "Prosocial Development in Late Adolescence: A Longitudinal Study," Child Development 66, no. 4 (1995), p. 1179.

85. Testing moral reasoning in hypothetical scenarios in which laws, authority and definite rules apply can mask the moral reasoning abilities of younger children. See Elliot Turiel, "The Development of Morality," in Handbook of Child Psychology. Volume 3, Social, Emotional, and Personality Development, ed. Nancy Eisenberg, 1 online resource (1 volume) (Hoboken, NJ: John Wiley, 2006), pp. 800, 824.

86. Ibid., pp. 824-25

87. Eisenberg et al., "Prosocial Development in Late Adolescence: A Longitudinal Study."

88. Ibid.

89. Daniel K. Lapsley, Moral Psychology (Boulder, CO: Westview Press, 1996), pp. 64-65, 78; "Moral Stage Theory," in Handbook of Moral Development, ed. Judith G. Smetana and Melanie Killen (Mahwah, NJ: Taylor and Francis, 2006), p. 49.

90. Lapsley, Moral Psychology, p. 68. also exhibit this level of reasoning. ${ }^{91}$ The crucial developmental transition away from such reasoning (and towards reasoning about relationships, virtues and societal level reasoning) generally occurs during the late elementary years and has occurred for most people, if not nearly everyone, by $13 .{ }^{92}$ And this level of reasoning is typical of both adults and adolescents. ${ }^{93}$ The point is stated clearly by Melton, who, in his review, concludes that:

the evidence is overwhelming that in fact most adolescents do have the capability to act as citizens of the moral community. ${ }^{94}$

\subsection{Complex Reasoning}

The previous sub-section described development in different modes of moral reasoning. Something else that develops across childhood is the ability to deal with more complex moral scenarios by coordinating the various morally and socially salient aspects of those scenarios. Nucci and Turiel (2009) investigated development in contextual moral decision-making and in how people coordinated different elements of moral decisions. They presented participants with three basic types of scenarios: direct harm (whether to hit another child); indirect harm (whether to return money to a child who unknowingly dropped it); and helping someone in need (whether to seek help for a child who falls and is injured). In each scenario, the researchers varied the cost of the moral action (i.e. whether it conflicted with the desires of the protagonist or was 'unconflicted') and the characteristics of the other child (whether they were simply a 'girl' or a 'boy', someone who had bullied the protagonist previously, or a vulnerable child). The study was conducted on 7 - to 17 -year-olds. ${ }^{95}$

All participants agreed that hitting another child unprovoked would be wrong. In scenarios where the other child hits the protagonist first, about half of the children at each age thought that the protagonist had the right to self-defence, though the percentage of 10- to 14-yearolds claiming this right was higher than for 8- and 16year-olds.

In the indirect harm scenario, someone unknowingly drops some money, and the protagonist must decide whether to return or keep the money. The participants

91. Anne Colby and Lawrence Kohlberg, The Measurement of Moral Judgment / Vol.2, Standard Issue Scoring Manual (Cambridge: Cambridge University Press, 1987).

92. Lawrence Kohlberg and Carol Gilligan, "The Adolescent as a Philosopher: The Discovery of the Self in a Postconventional World," Daedalus 100, no. 4 (1971), pp. 1051-86.

93. There are, however, some adults who never move beyond pre-conventional reasoning. Moshman, Adolescent Psychological Development: Rationality, Morality, and Identity, pp. 48-49; F. Clark Power, Ann Higgins-D'Alessandro, and Lawrence Kohlberg, Lawrence Kohlberg's Approach to Moral Education (New York: Columbia University Press, 1989), pp. 29-30; Kohlberg and Gilligan, "The Adolescent as a Philosopher: The Discovery of the Self in a Postconventional World."

94. Melton, "Are Adolescents People? Problems of Liberty, Entitlement, and Responsibility," p. 282.

95. Larry Nucci and Elliot Turiel, "Capturing the Complexity of Moral Development and Education," Mind, Brain, and Education 3, no. 3 (2009), p. 153. 


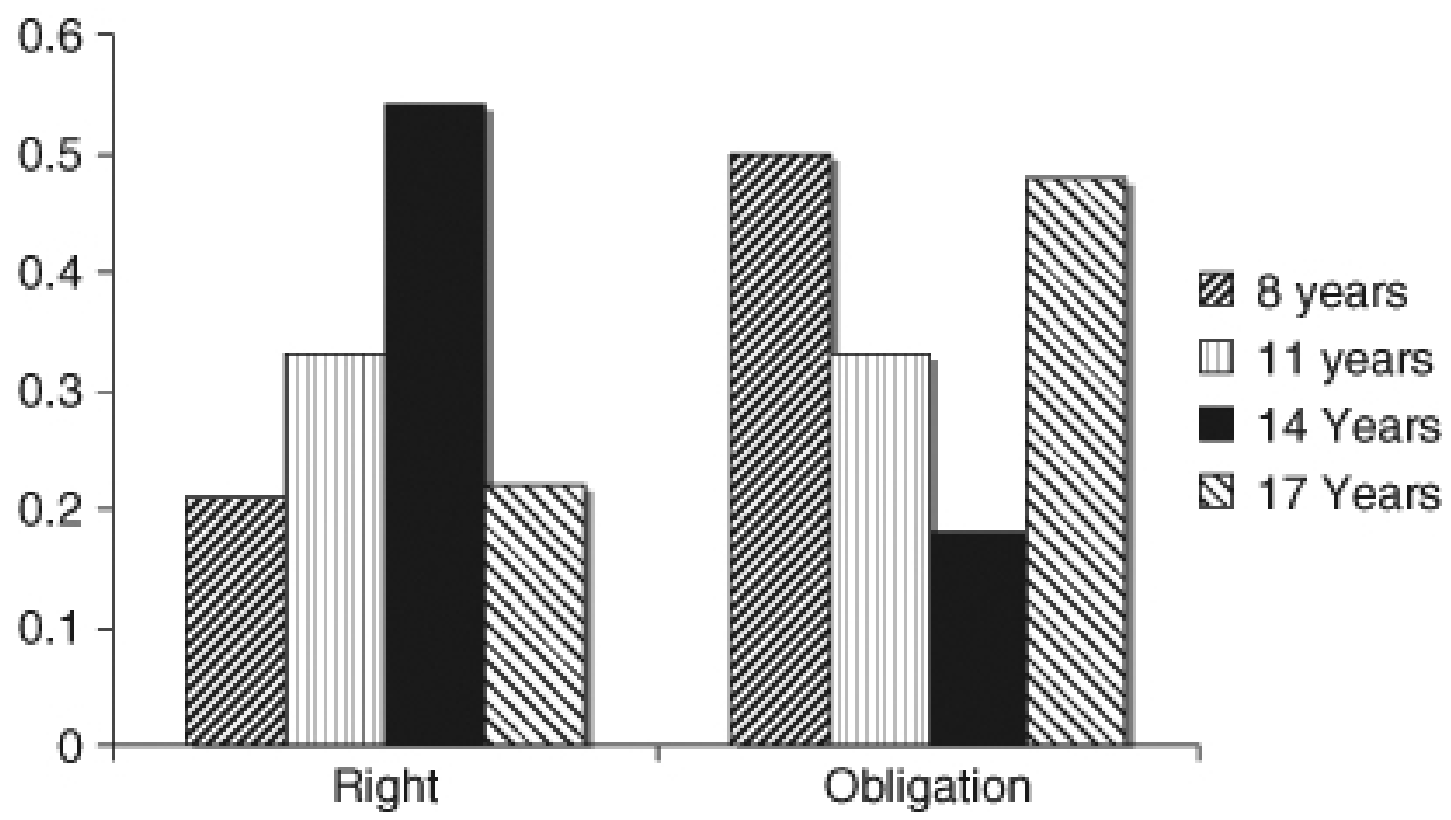

were asked whether the protagonist had a 'right' to keep the money or had an obligation to return it. The results are shown in Figure 1. For 8-year-olds the situation poses little ambiguity: to keep the money is the same as stealing it from the passenger's pocket. For the 14-yearold, however, the situation is more complex. Typical answers include:

he's not necessarily doing something wrong [in keeping the money], but the right thing to do would be to give it back ... [it's] not in the kid's house or anything.

For the 14-year-old, the ambiguity of the situation suggests that keeping or returning the money is a matter of personal prerogative. This mode of reasoning is more nuanced and sensitive to the facts of the situation than the 8-year-old's. By 16, most adolescents have resolved the ambiguity, seeing the situation as entailing a certain form of theft. They consider the indirectness of the theft to make it different from the act of intentional stealing, but they consider the protagonist's knowledge that the money originally belonged to someone else to place moral constraints on them. When the moral salience of the situation was upped and the child dropping the money was described as vulnerable or disabled, nearly all the participants said the money should be returned.

In the helping scenario, a child falls and is injured. Nearly all participants thought it would be wrong not to help. However, in scenarios where providing help conflicts with the protagonist's goals, or where the injured child had previously bullied the protagonist, 14-yearolds were less than half as likely as 8- and 16-year-olds to say the protagonist has an obligation to help. As with the other scenarios, the age-related pattern disappeared when the injured child was described as vulnerable. The results from the indirect harm and helping scenarios are represented in Figure 1.
This study shows that children and adolescents move from an early childhood set of judgments about unprovoked harm to notions of fairness and just reciprocity. Moreover, children become more able to incorporate multiple facets of moral situations; this then leads to periods of transition in which the expanded capacity to consider various aspects of moral situations leads to more variations in moral judgments. This is why we see the U-shaped patterns in the substantive answers to moral questions. Young children tend to focus on blunt moral aspects of the acts and are less likely to incorporate situational and non-moral features of the acts. The increased social and moral understandings of older children create more of a grey area in their minds, and hence a greater variability of answers. Older adolescents outperform their younger counterparts: early adolescents can spot and incorporate situational information; older adolescents can coordinate that information in ways that 'afforded a moral resolution while acknowledging competing nonmoral interests'. ${ }^{96}$ The results of this study show that, while individuals (as discussed earlier) from the age of 11 or 12 can reason using sophisticated moral principles, it is from the age of 16 that individuals can integrate and balance competing moral principles in complex or ambiguous moral dilemmas. Sections 4-8 together show that 16- to 17-year-olds have reached the threshold level of psychological development across all five of the core cognitive abilities needed for the two moral powers. As such, 16- to 17-year-olds possess the two moral powers and, with it, core autonomy. 


\section{Hierarchical Control and Impulsivity}

In this final section, I address the claim that adolescents may be too impulsive to vote. One important element of autonomous decision-making is 'hierarchical control', understood here as the ability to think about and control one's thoughts and motivations, and to regulate and control confounding internal factors, such as emotions, which can interfere with those mental processes needed for thought and action, and, in particular, the capacity to regulate and control the mental processes needed for the exercise of the two moral powers. ${ }^{97}$ While this is not a component of core autonomy as set out in Section 2, it is a second-order power needed to enable the operation of those powers, and to ensure autonomous decisionmaking. If you lack this power, then, while you possess the ability to formulate rational goals and plans, emotionality and impulses may interfere with that reasoning and frustrate your ability to make properly autonomous decisions.

Although adolescents have reached adult levels of cognitive capacity latest by age 16 , adolescents are not yet as developed as adults in psychosocial maturity (this is the psychological/behavioural expression of the neurological differences alluded to in p. 3). ${ }^{98}$ 'Psychosocial maturity' actually refers to a wide range of abilities and propensities, such as risk-seeking, sensation/pleasure-seeking, future-discounting and compliance with peer groups. ${ }^{99}$ A number of these are irrelevant to whether an individual has autonomy. It can be, for example, consistent with autonomous choice to be thrill-seeking (one can autonomously save money and plan for bungeejumping or skiing trips). Similarly, one can autonomously take greater risks, prioritise current over future benefits or prioritise social inclusion over individuality. However, impulse control is relevant to the capacity to make one's higher-order preferences and values effective in one's actions. To the extent someone lacks control over their impulses, they lack that hierarchical capacity to pursue self-chosen goals and values. More precisely, impulsivity 'refers to a lack of self-control or

97. On hierarchical accounts of autonomy, see Harry G. Frankfurt, "Freedom of the Will and the Concept of a Person," in The Inner Citadel: Essays on Individual Autonomy, ed. John Philip Christman (New York; Oxford: Oxford University Press, 1989), pp. x, 267 pages, 73; Gerald Dworkin, The Theory and Practice of Autonomy (Cambridge: Cambridge University Press, 1988), p. 20.

98. G. Icenogle et al., “Adolescents' Cognitive Capacity Reaches Adult Levels Prior to Their Psychosocial Maturity: Evidence for a 'Maturity Gap' in a Multinational, Cross-Sectional Sample," Law and Human Behaviour 43, no. 1 (2019), pp. 69-85; Laurence Steinberg et al., “Are Adolescents Less Mature Than Adults?: Minors' Access to Abortion, the Juvenile Death Penalty, and the Alleged APA 'Flip-Flop'," The American Psychologist 64, no. 7 (2009), pp. 583-94.

99. Steinberg et al., "Are Adolescents Less Mature Than Adults?: Minors' Access to Abortion, the Juvenile Death Penalty, and the Alleged APA 'Flip-Flop'," pp. 587-88. deficiencies in response inhibition', 100 and 'the extent to which one acts without thinking [and] has difficulty controlling impulses'. ${ }^{101}$ Impulsivity leads to hasty, unplanned behaviour, which is not reflective of one's autonomy.

In one of the key studies on impulsivity, Steinberg et al. (2008) find that impulsivity declines steadily and linearly from age 10 to $30 .{ }^{102}$ The development of impulse control seems to happen mainly in late adolescence and early adulthood. The 16- to 17-year-olds and the 18- to 21-year-olds in the study were significantly less impulsive than younger ages, but significantly more than the 22 - to 25-year-olds or the 26- to 30-year-olds. These results are also found in other studies using different scales of impulsivity or measuring psychosocial maturity more broadly. ${ }^{103}$ This suggests that while adolescents can make mature decisions in scenarios where cognitive capacity predominates, they may struggle in emotionally intense situations. ${ }^{104}$ This could suggest that while adolescents should be treated as adults 'for decisions typically made with deliberation', this may not be appropriate for decisions 'typically made in emotionally charged situations'. 105

Do these findings mean that teenagers should be denied the vote? Probably not. First, there is a case that although late adolescents have lower hierarchical control than older adults, they may not fall below the critical threshold needed for full autonomy. There is little difference between those 16- to 17-year-olds and 18- to 21year-olds in Steinberg et al.'s study. And indeed, 25\% of 14- to 15-year-olds have a level of psychosocial maturity above the mean for 26- to 30-year-olds. ${ }^{106}$ But second, and more important, voting is not the kind of 'hot', or emotionally charged decision where lower hierarchical control matters, meaning that their lower hierarchical control does not disqualify them from this

100. Laurence Steinberg et al., "Age Differences in Sensation Seeking and Impulsivity as Indexed by Behavior and Self-Report: Evidence for a Dual Systems Model," Developmental Psychology 44, no. 6 (2008), p. 1765.

101. Steinberg et al., "Are Adolescents Less Mature Than Adults? Minors' Access to Abortion, the Juvenile Death Penalty, and the Alleged APA 'Flip-Flop', " p. 588.

102. Steinberg et al., "Age Differences in Sensation Seeking and Impulsivity as Indexed by Behavior and Self-Report: Evidence for a Dual Systems Model," pp. 1771, 1774. See also L. Steinberg et al., "Around the World, Adolescence Is a Time of Heightened Sensation Seeking and Immature Self-Regulation," Developmental Science 21, no. 2 (2018),

103. See Adriana Galvan et al., "Risk-Taking and the Adolescent Brain: Who Is at Risk?," Developmental Science 10, no. 2 (2007), pp. F8-F14 on 7to 29-year-olds, and Rotem Leshem and Joseph Glicksohn, "The Construct of Impulsivity Revisited," Personality and Individual Differences 43, no. 4 (2007), pp. 681-91 on 14- to 22-year-olds. Also Steinberg et al., "Are Adolescents Less Mature Than Adults? Minors' Access to Abortion, the Juvenile Death Penalty, and the Alleged APA 'Flip-Flop'"; Laurence Steinberg and Elizabeth Cauffman, "Maturity of Judgment in Adolescence: Psychosocial Factors in Adolescent Decision Making," Law and Human Behavior 20, no. 3 (1996), pp. 249-72.

104. Icenogle et al., “Adolescents' Cognitive Capacity Reaches Adult Levels Prior to Their Psychosocial Maturity: Evidence for a 'Maturity Gap' in a Multinational, Cross-Sectional Sample."

105. Ibid., p. 70.

106. Steinberg et al., "Are Adolescents Less Mature Than Adults? Minors' Access to Abortion, the Juvenile Death Penalty, and the Alleged APA ‘Flip-Flop'," p. 591. 
right. Voting does not lend itself to the kinds of intense emotionality that some adolescents struggle with. Adolescents suffer from cognitive slippage in decision-making in scenarios such as acute hospitalisation, intoxication or under the stress of police questioning. ${ }^{107}$ But voting is unlike those scenarios. In fact, voting is considered a typical case of 'cold cognition', where the final decision is made in the absence of high emotion. ${ }^{108}$ After all, political decisions are taken after weeks, if not months, of political campaigning to give space to slow deliberation. The final decision itself is normally made in the sober atmosphere of a polling booth. Even if a decision is made 'on the spur of the moment', that does not mean that emotionality or impulse inhibited the exercise of reason. ${ }^{109}$ Indeed, existing work on political decision-making among teenagers suggests that impulsivity does not affect their decision-making:

To date, there is no neurological evidence that indicates that 16- and 17-year-olds lack the requisite neurological maturation necessary for citizenship or for responsible voting. ${ }^{110}$

And in countries where 16- to 17-year-olds have been allowed to vote, the quality of their choices became similar to that of older voters, and there is

no convincing evidence that the voting decisions of voters under 18 are in any way of lesser quality ... than that of older groups of voters. ${ }^{111}$

Quality of voter choice is here the level of ideological congruence between the voters and the party they vote for. This suggests that emotionality and impulsivity is not interfering with the connection between 16- and 17year-olds' political views and their decisions any more than it does for adults.

Therefore, although adolescents possess the full cognitive powers that constitute the two moral powers, impulsivity could indicate an autonomy-based reason for adolescents (especially younger adolescents) to have different rights or have their rights respected differently

107. On hospitalisation scenarios, see P. Harris and M.S. Lipian, "Understanding Emotion and Experiencing Emotion," in Children's Understanding of Emotion, ed. Paul L. Harris and Carolyn Saarni (Cambridge: Cambridge University Press, 1989), quoted in Carolyn Saarni et al., "Emotional Development: Action, Communication, and Understanding," in Handbook of Child Psychology. Volume 3, Social, Emotional, and Personality Development, ed. Nancy Eisenberg (Hoboken, NJ: John Wiley, 2006), p. 277. Also Steinberg, “Adolescent Brain Science and Juvenile Justice Policymaking," p. 411.

108. Icenogle et al., "Adolescents' Cognitive Capacity Reaches Adult Levels Prior to Their Psychosocial Maturity: Evidence for a 'Maturity Gap' in a Multinational, Cross-Sectional Sample," p. 71.

109. It is important to distinguish impulsivity and spontaneity. A spontaneous action involves quick decisions made in light of higher-order goals. Impulsiveness, on the other hand, is characterised more by the absence of decision. The distinguishing feature of an impulse is that one has reduced control over whether to follow that impulse.

110. Hart and Atkins, "American Sixteen-and Seventeen-Year-Olds Are Ready to Vote," p. 220

111. Wagner, Johann, and Kritzinger, "Voting at 16: Turnout and the Quality of Vote Choice," p. 380. from adults. But considering that (i) adolescents may not fall below the critical threshold of hierarchical control in general, (ii) voting does not usually involve the kind of emotionality that some teenagers struggle with, and (iii) the evidence suggests adolescent impulsivity is not a barrier to their political decision-making, it seems unlikely to indicate a reason that they should not vote.

\section{Conclusion}

This article has examined the normative grounds for the right to vote, and then seen empirically whether 16- and 17-year-olds meet the criteria to qualify for the franchise. I have advanced the view that respect for autonomy grounds the right to vote. Taking the Rawlsian two moral powers as the exemplar for autonomy, I laid out the psychological capacities that correspond to the two moral powers. Finally, I summarised findings from empirical psychology that suggest that 16- and 17-yearolds, and some younger adolescents, possess those two moral powers. From the evidence laid out above, it seems generally that there is little discernible difference in cognitive ability between (older) adolescents and adults. Examining their cognitive abilities as aggregate groups, it can be difficult to distinguish adolescents from adults. ${ }^{112}$ Indeed,

cognitive differences among adolescents and adults are not related strongly to age ... [most adults] never proceed beyond the level of an average adolescent and many adolescents function more rationally than an average adult. ${ }^{113}$

Therefore, 16- and 17-year-olds have a pro tanto right to vote. And while adolescents may have less hierarchical control than older adults, this does not disqualify from the franchise, first, because it is not clear they fall below a critical threshold and, second, because voting is not the kind of 'hot' decision where emotionality is a problem for the operation of core autonomy. However, the argument here has not definitely shown that the voting age should be lowered: it has not established the autonomy account, and if one rejected those accounts, then this argument to lower the franchise will not be convincing. Moreover, the argument here only provides a pro tanto moral right to vote for 16- and 17-year-olds. If there were, for example, significantly negative consequences to letting them vote, that might defeat this right (although the evidence from places they can vote do not suggest such negative consequences). ${ }^{114}$

So, since adolescents aged 16 and 17 (and quite probably those a little younger) possess the natural features required for autonomy, then, to the extent that respect for autonomy requires granting political rights including

112. Moshman, Adolescent Psychological Development: Rationality, Morality, and Identity, p. 6

113. Ibid., p. 40

114. Peto, "Why the Voting Age Should Be Lowered to 16." 
the right to vote - and barring some special circumstances that apply only to them - 16- and 17-year-olds should be granted the right to vote.

What do the findings here imply for other rights? Generally, the findings suggest that for 'cool' decisions, which are not typically made in situations of intense emotionality, adolescents possess the same moral rights as adults. What that should mean for legal rights will depend on the right in question, and on a range of practical factors. For 'hot' decisions, the argument here still leaves open what the correct response is. Are adolescents above the critical threshold required for full adult rights? If not, do we deny them decisions in such scenarios or merely facilitate their decision-making? Such questions are left for further avenues of research. 